\title{
Coupling of SUFI 2 and SWAT for Improving the Simulation of Streamflow in an Agricultural Watershed of South Dakota
}

\section{Sushant Mehan ${ }^{1}$, Ram P Neupane ${ }^{2}$ and Sandeep Kumar ${ }^{3 *}$}

${ }^{1}$ Agricultural and Biological Engineering, Purdue University, West Lafayette, IN 47906, USA

${ }^{2}$ Indiana University, Bloomington, IN, USA

${ }^{3}$ Department of Plant Science, South Dakota State University, Brookings, SD 57007, USA

\begin{abstract}
Calibration and validation of process based hydrological models are two major processes while simulating the water balance components of watershed systems. However, these processes need a better understanding of the parameters which influence hydrologic processes within the system. In this study, we used SWAT model to simulate the stream flow for Skunk Creek (SK) watershed in South Dakota for the period from 1980-2000. Model calibration and validation were performed for both daily and monthly time periods using SUFI-2 within SWAT-CUP using 24 parameters selected from past available literature. Our calibration outputs for the period from 1987-1994 showed a good correlation between observed and model simulated values with $N S E=0.56$ and $R^{2}=0.70$ for daily simulation. However, the model showed a better performance for monthly simulation with NSE and $R^{2}$ values of 0.84 and 0.84 respectively. During validation period (1995-2000), the NSE and $r^{2}$ values were 0.55 and 0.44 , respectively for daily simulation and these statistical values were 0.76 and 0.77 , respectively for monthly time step. Following calibration, the overall effect of each parameter used was ranked using global sensitivity function within SWAT-CUP. From the analysis, SOL_AWC was found to be the most sensitive parameter with absolute t-value of 17.50 and $p$-value of 0.00 to simulate the stream flow of the SK watershed. The $\mathrm{CH}_{-} \mathrm{K} 2$ was observed as the least sensitive parameter with t-statistic and p-value of 0.02 and 0.97 , respectively. It was concluded from the study that coupling of the SWAT and SWAT-CUP made the calibration process quicker and reliable to simulate local hydrology within the watershed.
\end{abstract}

Keywords: Uncertainty analysis; Calibration; Validation; SUFI-2; SWAT; Sensitivity analysis

\section{Introduction}

Hydrologic models are widely used across the globe to simulate hydrologic processes including quality and quantity of stream flow in a basin [1]. It is highly labor, time, and cost intensive for maintaining gauging stations to collect water quality and quantity from a number of locations for long-term [2]. Therefore, hydrologic models play a significant role in simulating various hydrologic processes such as water quantity and quality, rainfall- runoff conceptualization, and sediment yield. There are ranges of models that are available for simulating longterm trends of hydrologic processes at small and larger watershed scales. Some of widely used hydrologic models include: Hydrological Simulation Program-Fortran (HSPF) [3], Systeme Hydrologique Europeen (SHE) [4], MIKE SHE [5], SHETRAN [6], Soil and Water Assessment Tool (SWAT) [7], Topographic Model (TOPMODEL) [8,9], and MOHID Land [10]. Of these, SWAT, a distributed process-based river basin continuous hydrologic model [7] is the most commonly and widely applied tool for simulating the management and climate change impacts on hydrologic processes at watershed scales.

SWAT model has been extensively used across the globe for assessing the long-term management [11], land use and climate change $[1,12-16]$ impacts on water quantity and quality at watershed scales. The development of SWAT is a continuation of United States Department of Agriculture-Agricultural Research Service (USDAARS) modeling experience that spans a period of over 30 years $[17,18]$. Accurate calibration of hydrologic models (including SWAT) is very important in assessing the water budget of a watershed for sustainable water resources management [19]. Improvement in calibration of models for better simulation of water quantity and quality has become a major topic of research among hydrologists. However, there are many uncertainties involved while working with hydrologic models that arise due to large spatial variability and multitude of input parameters [20]. These uncertainties over and under estimate the hydrologic processes, and can lead to wrong decisions [21]. Therefore, it is crucial to carefully carry the calibration and uncertainty analysis of hydrologic models for improved simulations [22-24].

To perform successful calibration and uncertainty analysis, there are various methods available that include such as parameter solution (PARASOL), Adaptive Clustering Covering (ACCO), general algorithm (GA), multi-start (M-Simplex), SWAT-CUP (including GLUE, SUFI2, MCMC, PARASOL, and PSO), and uncertainty estimation based on local error and clustering (UNEEC). Among these, the Sequential Uncertainty Fitting 2 (SUFI-2) approach with SWAT Calibration Uncertainty Procedure (SWAT-CUP) is the most widely used approach to carry out parameterization, sensitivity analysis, uncertainty analysis, calibration, and validation of hydrologic parameters on both daily and monthly time-step [25]. The SUFI-2 is a semi-automated approach that makes the calibration process easier to carry within the realizable time bounds [26]. It has gained more interest among researchers for the reason that if it carried out manually, the incorporation of large

*Corresponding author: Sandeep Kumar, Assistant Professor, South Dakota State University, Brookings, SD 57006, USA, Tel: +1-605-688-4306; E-mail: Sandeep.Kumar@sdstate.edu

Received June 21, 2017; Accepted August 02, 2017; Published August 08, 2017

Citation: Mehan S, Neupane RP, Kumar S (2017) Coupling of SUFI 2 and SWAT for Improving the Simulation of Streamflow in an Agricultural Watershed of South Dakota. Hydrol Current Res 8: 280. doi: 10.4172/2157-7587.1000280

Copyright: @ 2017 Mehan S, et al. This is an open-access article distributed under the terms of the Creative Commons Attribution License, which permits unrestricted use, distribution, and reproduction in any medium, provided the original author and source are credited. 
number of parameters in a model can make the calibration process more complex and computationally extensive $[27,28]$.

The first step in building any successful and reliable predictive hydrologic model is to carry Sensitivity Analysis (SA) which is helpful to identify and rank the parameters that have significant impact on specific model outputs of interest [29]. In SUFI-2, the techniques employed to perform the SA involves one-at-a time (OAT or Local Analysis) and Global Sensitivity Analysis methods. The OAT approach identifies the response from the output by sequentially varying each model parameter by a certain fraction while others are kept at their normal values [30-32]. This approach is less reliable as the parameter perturbation results in eccentricity from the nominal parameter value [33]. On the other hand, Global Sensitivity Analysis explores the entire range of the parameter values during model simulation process. In this method, all the parameters under consideration are simultaneously perturbed, allowing investigation of parameter's interaction and their influence on model outputs. This approach has the potential to capture the full range of model parameter values, and also to identify the interactions among parameters [34]. These two approaches yield different results [35], and therefore, it is always recommended to undergo comprehensive evaluation of parameter sensitivity [36].

There are number of factors involved in successful calibration of SWAT model such as parameter sensitivity, number of simulations, number of iterations, uncertainty associated among the parameters. Therefore, the specific objective of this study was to simulate the stream flow of an agricultural dominated watershed with minimum uncertainty among the parameters, and high reliability in predicting them using SWAT model coupled with SUFI-2 approach.

\section{Materials and Methods}

\section{Study watershed}

The present study was conducted for the Skunk Creek Watershed (SCW) located in the eastern part of South Dakota (SD) (Figure 1). The Skunk Creek is one of the main tributaries of the Big Sioux River. The Skunk Creek is $118 \mathrm{~km}$ permanent natural creek lying between 97.35$96.74^{\circ}$ West and $43.45-44.13^{\circ}$ North. The SCW covers an area of 1,606 $\mathrm{km}^{2}$ and has its spread within six different counties of SD including Lake, Moody, Minnehaha, McCook, Lincoln, and Turner. The elevation of the watershed ranges between 351 and $574 \mathrm{~m}$ above mean sea level. The land use of the study watershed is dominated by cropland: corn (38\%), soybean $(26 \%)$, and pastures $(14 \%)$. The c texture is dominated by silt clay loam with a few gravelly loams, loams, silt loams, loamy sand, and silt clay [37]. The average annual precipitation is about 590 $\mathrm{mm}$, of which major proportion typically falls during the months from April to September. The average snowfall is $930 \mathrm{~mm}$ per year [37]. The average daily maximum and minimum temperature values are $15.5^{\circ} \mathrm{C}$ and $2.8^{\circ} \mathrm{C}$, respectively.

\section{SWAT model}

The ArcGIS enabled SWAT model (version 2012) used for this study. The SWAT is an effective tool for evaluating the long-term impacts of management on hydrologic processes of diverse watershed systems $[12,13,38,39]$. In addition, this model also estimates the climate change impacts on plant growth, stream flow, and other responses such as total water yield, ET, snowmelt, and many others by taking into account the effects of increased atmospheric $\mathrm{CO}_{2}$ concentrations on plant development and transpiration [40,41].

In SWAT, watershed hydrology is simulated in two major phases:

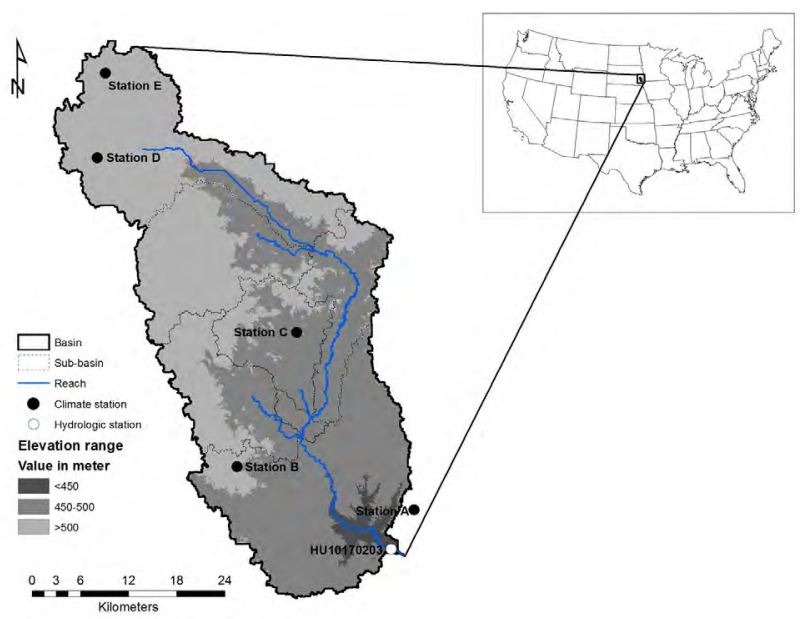

Figure 1: The Skunk Creek watershed located in north-central part of the United States is shown with the hydro-meteorological stations used in this study.

land phase and routing phase [42]. The land phase controls the amount of water, sediment, nutrient, and pesticide loadings to the main channel in each sub-basin, whereas, the routing phase regulates the movement of these materials through the channel networks to the outlet of a watershed. The water balance equation that governs the land phase of hydrological cycle is given by the Equation 1 shown below as:

$$
S W_{t}=S W_{0}+\sum_{i=1}^{t}\left(R_{d a y}-Q_{\text {suf }}-E_{a}-W_{\text {seep }}-Q_{g w}\right)
$$

where $S W_{t}$ is final soil water content $\left(\mathrm{mm} \mathrm{H}_{2} \mathrm{O}\right), S W_{o}$ is initial soil water content $\left(\mathrm{mm} \mathrm{H}_{2} \mathrm{O}\right), t$ is time (days), $R_{d a y}$ is amount of precipitation on day $\left(\mathrm{mm} \mathrm{H}_{2} \mathrm{O}\right), Q_{\text {surf }}$ is amount of surface runoff $\left(\mathrm{mm} \mathrm{H}_{2} \mathrm{O}\right), E_{a}$ is amount of evapotranspiration $\left(\mathrm{mm} \mathrm{H}_{2} \mathrm{O}\right), W_{\text {seep }}$ is amount of water entering the vadose zone from the soil profile $\left(\mathrm{mm} \mathrm{H}_{2} \mathrm{O}\right)$, and $Q_{g w}$ is amount of return flow $\left(\mathrm{mm} \mathrm{H}_{2} \mathrm{O}\right)$. The potential evapotranspiration in the model can be computed by three different approaches: Hargreaves [43], Priestley-Taylor [44], and Penman Monteith [45]. However, Penman- Monteith model was used for this study that incorporates energy and aerodynamic considerations [46]. To estimate the surface runoff, we used the Soil Conservation Service (SCS) Curve Number (CN) method [47] as shown below in Equation 2 which uses local land use, soil type, and antecedent moisture conditions.

$$
S=25.4\left(\frac{1000}{C N}-10\right)
$$

where $Q_{\text {surf }}$ is accumulated runoff or rainfall excess $\left(\mathrm{mm} \mathrm{H}_{2} \mathrm{O}\right), R_{d a y}$ is rainfall depth for the day $\left(\mathrm{mm} \mathrm{H}_{2} \mathrm{O}\right), I_{a}$ is initial abstraction which includes surface storage, interception and infiltration prior to runoff $\left(\mathrm{mm} \mathrm{H} \mathrm{H}_{2} \mathrm{O}\right)$, and $S$ is the retention parameter $\left(\mathrm{mm} \mathrm{H}_{2} \mathrm{O}\right)$. The $I_{a}$ was commonly approximated as $0.2 S$ [47]. Therefore, the surface runoff will occur when $R_{d a y}>I_{a}$. The retention parameter $\mathrm{S}$ was computed as presented in the following Equation 3.

$$
S=25.4\left(\frac{1000}{C N}-10\right)
$$

where $C N$ is curve number for the day. The retention parameter which governs the value is spatially variable which is primarily based on local land use type and soil water content [42].

The SWAT has an embedded tool to reduce uncertainty through analyzing sensitivity of the parameters. It uses a method which is a 
combination of Latin hypercube and one factor-at-a time sampling that allows global sensitivity analysis for various parameters with only limited number of model runs [21]. Therefore, it necessitates to run the model multiple times for better accuracy of the model simulation outputs. In our study, both the calibration and sensitivity analyses were carried out using semi-automated stochastic model, the SWAT-CUP. We performed the global sensitivity analysis where the parameter sensitivities were determined by calculating multiple regression system as presented in the Equation 4.

$$
g=\alpha+\sum_{i=1}^{m} \beta_{i} b_{i}
$$

where $g$ is the objective function, $\alpha$ and $\beta$ are the variables and $b$ is parameter. A t-test was then used to identify the relative significance of each parameter $b_{i}$ through the application of inverse optimization approach.

\section{Data source and analysis}

Data on topography, land use, soil, climate, and stream discharge required for this study were compiled from different sources. The Digital Elevation Model (DEM) of $10 \mathrm{~m}$ by $10 \mathrm{~m}$ resolution was derived from Geospatial Data Gateway (GDG) to use as topographic data of the study basin. The DEM is required for delineating a watershed into sub-basins and then into smallest representative unit of the watershed, the Hydrologic Response Units (HRUs) based on specific land use, soil, and slope characteristic features. Land use map for this study was obtained in the form of Cropland Data Layer (CDL) which is created by USDA, National Agricultural Statistics Service (NASS). A CDL is a raster, geo-referenced, crop specific land cover dataset created annually for continental US using moderate resolution $(30 \mathrm{~m}$ and $56 \mathrm{~m}$ ) satellite imagery and extensive agricultural ground truth. The soil map was obtained from Soil Survey Geographic Data (SSURGO) collected by National Cooperative Soil Survey (NCSS), USDA, and Natural Resources Conservation Services (NRCS) with the scales ranging from 1: 12,000 to $1: 63,360$ [48]. All these spatial datasets were set to the projection of WGS-1984 UTM Zone 14N using ArcGIS (version 10.0) for further simulations.

Similarly, the SWAT requires meteorological daily data inputs such as precipitation, maximum and minimum air temperature, wind speed, relative humidity, and solar radiation for hydrologic simulations. For the current study, the temperature and precipitation data were extracted from Daily Surface Weather and Climatological Summaries (DAYMET) Single Point Data Extraction (SPDE) $[49,50]$ for five different spatial locations as Stations A, B, C, D, and E, and presented in the Figure 1 and Table 1 . This dataset is available on a daily time scale with the resolution of $1 \mathrm{~km} \times 1 \mathrm{~km}$, and supported by the funding from National Aeronautics and Space Administration (NASA) through Earth Science Data and Information System (ESDIS) and terrestrial Ecosystem Program. This is commonly used meteorological dataset used by hydrologists across the globe for simulating hydrologic processes $[13,51,52]$. Temperature and precipitation data were derived from five weather stations located within the basin and named as Stations A, B, C, D, and E as shown in the Figure 1 and Table 1. The remaining meteorological inputs were automatically generated within the SWAT using daily precipitation and temperature data. Simulated stream discharge outputs from the generated model were compared with stream discharge taken from the USGS site no 06481500 located at Sioux Falls, SD for the period from 1987-2000. Detailed description of hydro-meteorological stations chosen for the study is presented in Table 1.

\section{SWAT model set-up and calibration}

After incorporating all the data inputs, the SWAT model was built with the total of 7 sub-basins and 364 Hydrological Response Units (HRUs). First, the model was set to run for 1980-2000 with the initial 7 years (1980-86) as model warm-up period that allows the model to stabilize for further simulations. Then, the consequent phases were established as calibration (1987-1994) and validation (19952000) periods. This was done with care so as to ensure that both the periods should nearly have same water balance values. Calibration and validation of the model were done using the SUFI-2 approach within SWAT-CUP considering 24 key hydrologic parameters based on detailed previous literature sources $[53,54]$. Then, each parameter was set to a default lower and upper values as suggested by the SWAT expert group [42]. Finally, the best fitted parameter values obtained from SWAT-CUP were incorporated into the SWAT database for stream discharge simulations at both daily and monthly time steps. The model performance was evaluated using Nash-Sutcliffe efficiency (NSE) $[55,56]$ coefficient of determination $\left(R^{2}\right)$, and percentage of bias (PBIAS) [57] indices as presented in the following Equations 5-7.

$$
\begin{aligned}
& \text { PBIAS }=\frac{\sum\left(Y^{\text {obs }}-Y^{\text {sim }}\right)}{\sum Y^{\text {obs }}} \times 100 \\
& \text { PBIAS }=\frac{\sum\left(Y^{\text {obs }}-Y^{\text {sim }}\right)}{\sum Y^{\text {obs }}} \times 100 \\
& R^{2}=\frac{\sum_{i}\left[\left(Y^{\text {obs }}-Y_{0}^{\text {mean }}\right)\left(Y^{\text {sim }}-Y_{s}^{\text {mean }}\right)\right]^{2}}{\sum_{i}\left(Y^{\text {obs }}-Y_{0}^{\text {mean }}\right)^{2} \sum_{i}\left(Y^{\text {sim }}-Y_{s}^{\text {mean }}\right)^{2}}
\end{aligned}
$$

where, $Y^{o b s}$ is the measured data, $Y^{\text {sim }}$ is the model simulation output, and $Y_{o}^{\text {mean }}$ and $Y_{s}^{\text {mean }}$ is the mean of observed data and simulated data of stream flow, and $m$ and $s$ stand for measured and simulated, $i$ is the $i^{\text {th }}$ measured or simulated data.

\section{SUFI-2 algorithm}

Figure 2 demonstrates the schematic flow of processes those are involved while operating the SUFI-2. First, the objective function

\begin{tabular}{|c|c|c|c|c|c|}
\hline S. No. & Description & Type & Latitude & Longitude & Elevation (m) \\
\hline 1 & Station A & Meteorology & 43.57 & -96.75 & 432 \\
\hline 2 & Station B & Meteorology & 43.63 & -97.02 & 504 \\
\hline 3 & Station C & Meteorology & 43.78 & -96.92 & 488 \\
\hline 4 & Station D & Meteorology & 43.99 & -97.23 & 543 \\
\hline 5 & Station E & Meteorology & 44.08 & -97.21 & 544 \\
\hline 6 & HUC10170203 & Hydrology & 43.53 & -96.79 & 427 \\
\hline
\end{tabular}

Table 1: Description of hydro-meteorological stations in the Skunk Creek Watershed. 


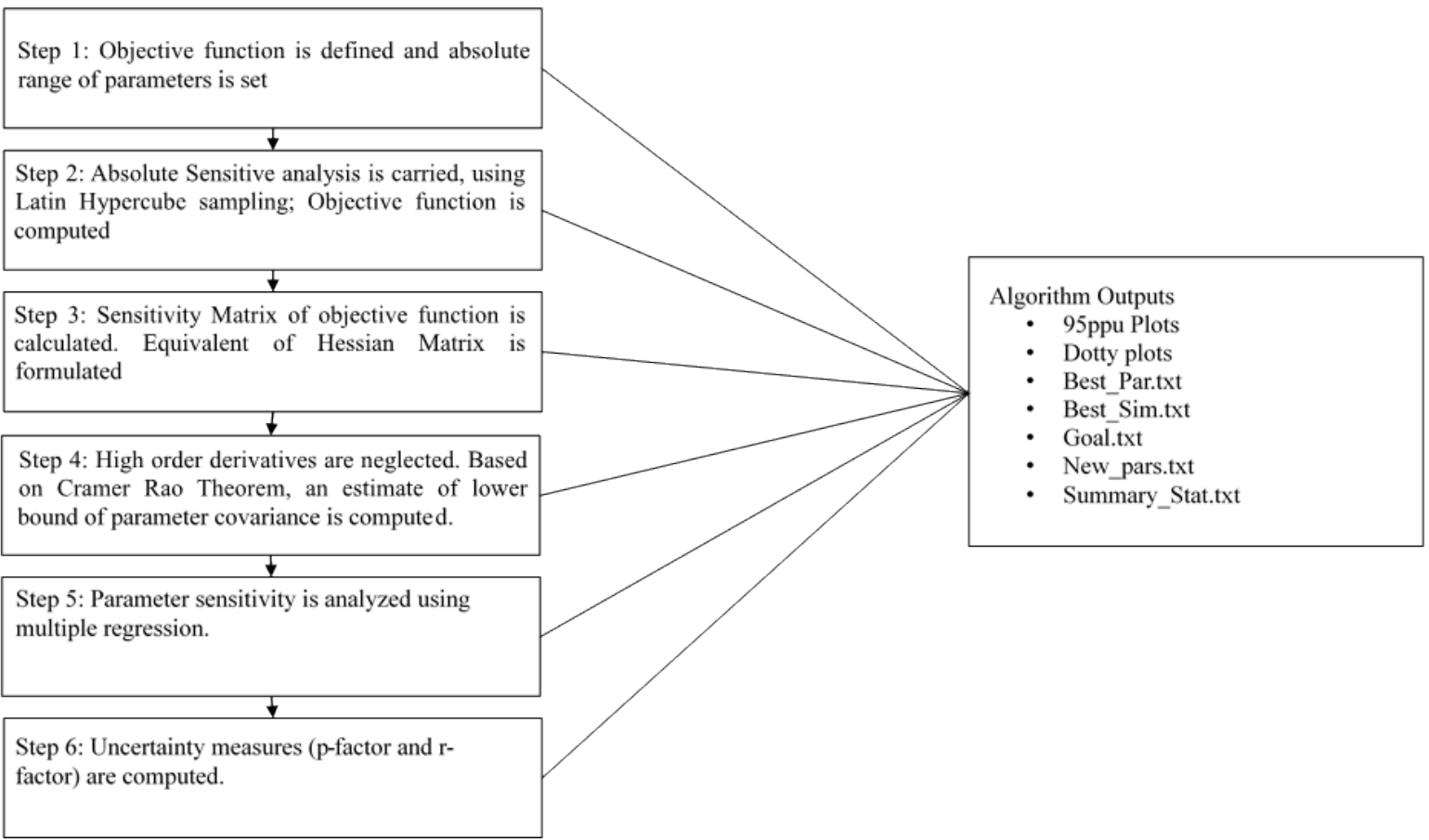

Figure 2: Schematic representation to show different work steps in SUFI-2 followed in this study to reduce the parameter uncertainty.

(here to maximize the NSE) was defined. Then, the algorithm optimizes absolute maximum and minimum range of the parameters. It was assumed that all the parameters were uniformly distributed within the region bounded by these range of values. The SUFI-2 algorithm was designed in a manner that no automated optimization routine can replace the insight from physical understanding and knowledge of the effects of parameters on system response. Further, first round of Latin hypercube sampling [58] took place, where initial uncertainty ranges were next assigned to parameters, making parameter combinations. Following the Gaussian Newton method and neglecting higher order derivatives, equivalent of Hessian matrix was then calculated. Based on Cramer Rao theorem [59], an estimate of the lower bound of parameter covariance matrix was computed. It was observed that there was quite small correlation between any two parameters; as all parameters were allowed to change. This was because in SUFI-2, all the parameters are kept constant while a change is brought in one only at a time [60].

Global Sensitivity Analysis (GSA) was used to carry out sensitivity analysis of the parameters chosen for the calibration process. In this process, multiple regression system regress Latin hypercube generated parameters against objective function to determine sensitivity of the parameters. As statistical measurements, $t$-stat and $p$-value were used. A $t$-stat is the coefficient of a parameter divided by its standard error and is a measure of the precision with which the regression coefficient is measured. Therefore, the parameter is sensitive when the coefficient is larger than the standard error [60]. A $p$-value was determined from student's $t$-distribution table with the values obtained for $t$-stat for a parameter; where a lower $p$-value suggests higher sensitivity of the parameter, and vice-versa [60]. The overall uncertainty in the output was computed by 95 Percent Prediction Uncertainty (95 PPU) and dotty plots for each parameter. This helped in determining the new ranges and best fitted values that were applied for further iterations to maximize the objective function. The 95 PPU was calculated at 2.5 and $97.5 \%$ levels of the cumulative distribution of an output variable obtained through Latin hypercube sampling. Two indices were used to quantify the goodness of calibration/uncertainty performance: the $p$-factor, which is the percentage of data bracketed by the 95 PPU band (ideal value should approach closer to 1 ) and the $r$-factor, which is an average width of the band divided by standard deviation of the corresponding measured variable (ideal value should be close to 0 ). To minimize uncertainties and maximize the objective function, the number of sampling round was increased with the set of new parameter ranges. However, care was taken for using the physical acceptable parameter values for this process.

\section{Results and Discussion}

\section{Climate and stream discharge data, and model performance}

The climate data collected for 1987-2000 showed that the higher precipitation was received from April to September with the maximum value of $105 \mathrm{~mm}$ in June, and minimum value of $12.4 \mathrm{~mm}$ in December (Figure $4 \mathrm{a}$ ). Nearly, $40 \%$ of total precipitation was received during summer season of the study period. The average monthly maximum stream flow $\left(293 \mathrm{~m}^{3} / \mathrm{s}\right)$ was observed in the month of April. A total of about $49 \%$ of cumulative stream flow cumulated on seasonal basis was observed during the spring season (Figure $4 \mathrm{~b}$ ). The higher stream flow during spring season can be attributed to the fact that the snow melt water dominantly contributes during this season [61].

The model evaluation coefficients of the simulated daily stream discharge are presented in Table 2 . The $R^{2}$ and NSE values for calibration (1987-94) were 0.70 and 0.56 , respectively, whereas these values were 0.55 and 0.44 for the validation period (1995-2000). The model showed better performance for the monthly simulations with $R^{2}$ and NSE values as 0.84 and 0.84 , respectively, for the calibration, and 0.77 and 0.76 for the validation period. The measured and simulated stream discharge values were represented in the hydrographs shown in Figure 3. The 

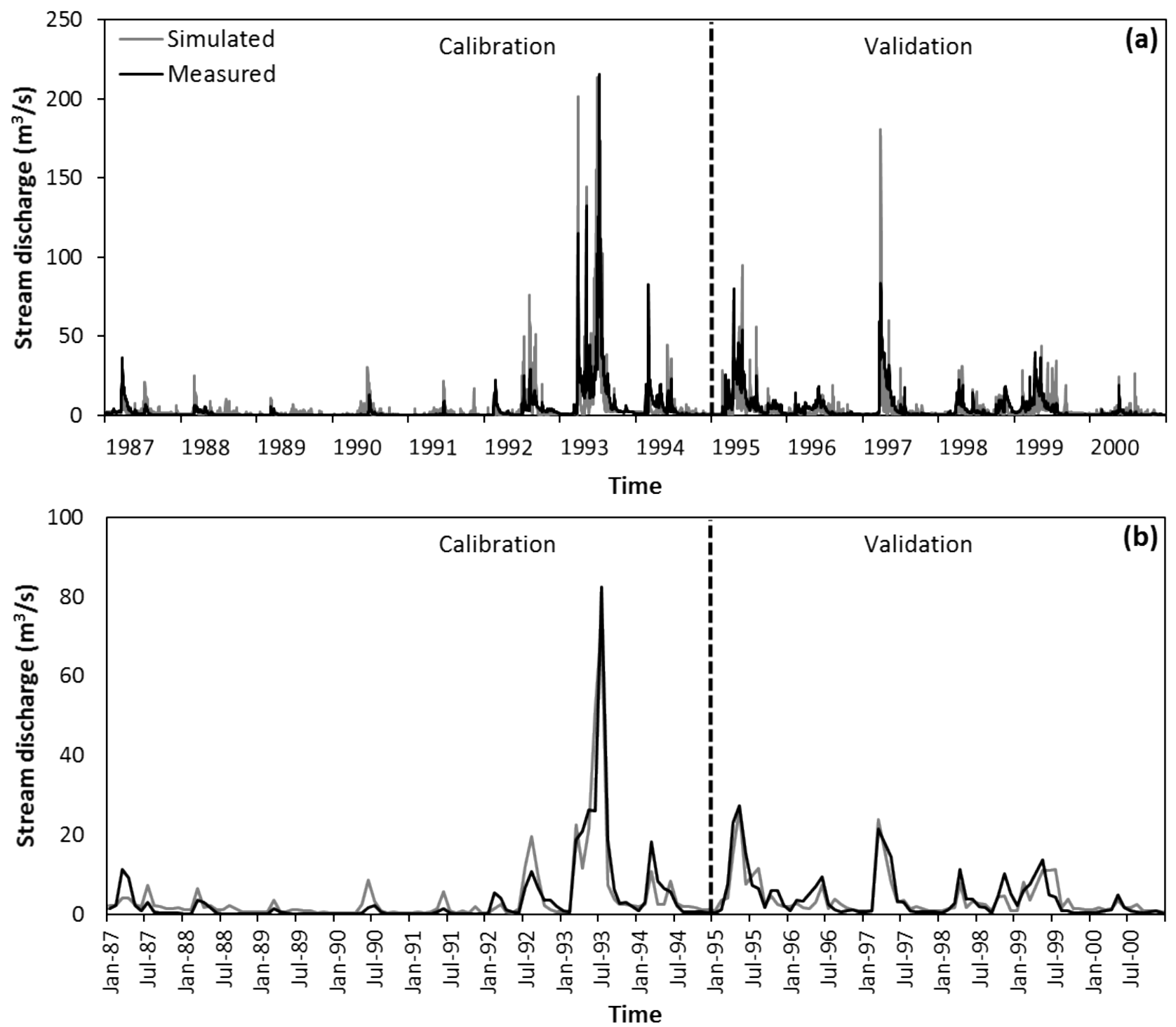

Figure 3: Hydrographs obtained during model calibration and validation periods for daily (a) and monthly (b) time periods [73].

model outputs revealed that the model is satisfactory in simulating the stream flow for the study watershed [55].

\section{PPU plots}

The hydrographs of 95 PPU plots derived from two different iterations (500 and 2000 simulations) are presented in the Figure 5. The $\mathrm{p}$-factor and $\mathrm{r}$-factor values were 0.57 and 0.90 , respectively, for the 500 simulations. However, the factor values were 0.65 and 0.94 for the 2000 simulations obtained with the same set of input parameters. The combination of $\mathrm{p}$-factor and $\mathrm{r}$-factor together indicates the strength of model calibration and uncertainty assessment, as these are intimately linked [60]. The data showed that by keeping all the conditions same, the different number of model simulations produced different results for uncertainty indices, and therefore, affecting the goodness-of-fit. This approach of comparing two different simulations helped for better assessment of model uncertainties. The p-factor in either case was found to achieve desirable values $[15,24,62]$. The large $r$-factor values may be attributed to insufficient accounting of agricultural water use in the model [62] and inter-basin water transfer [63]. However, a reexamination of the conceptual model was needed if the $\mathrm{p}$-factor value does not lie within the proposed acceptable range [64].

\section{Parameter sensitivity}

The most sensitive input hydrologic parameters identified on the basis of global sensitivity analysis and used for stream discharge simulations are presented in Table 3. We found different ranking of the same parameter with different simulation numbers, indicating the stochastic nature of the SWAT-CUP [65]. However, for both the simulations, the SOL_AWC and CN2 were observed as the most sensitive parameters to influence stream discharge of the basin. This was due to the reason that SOL_AWC represents the soil moisture characteristics, and plays an important role in evapotranspiration to influence the surface runoff [66]. 

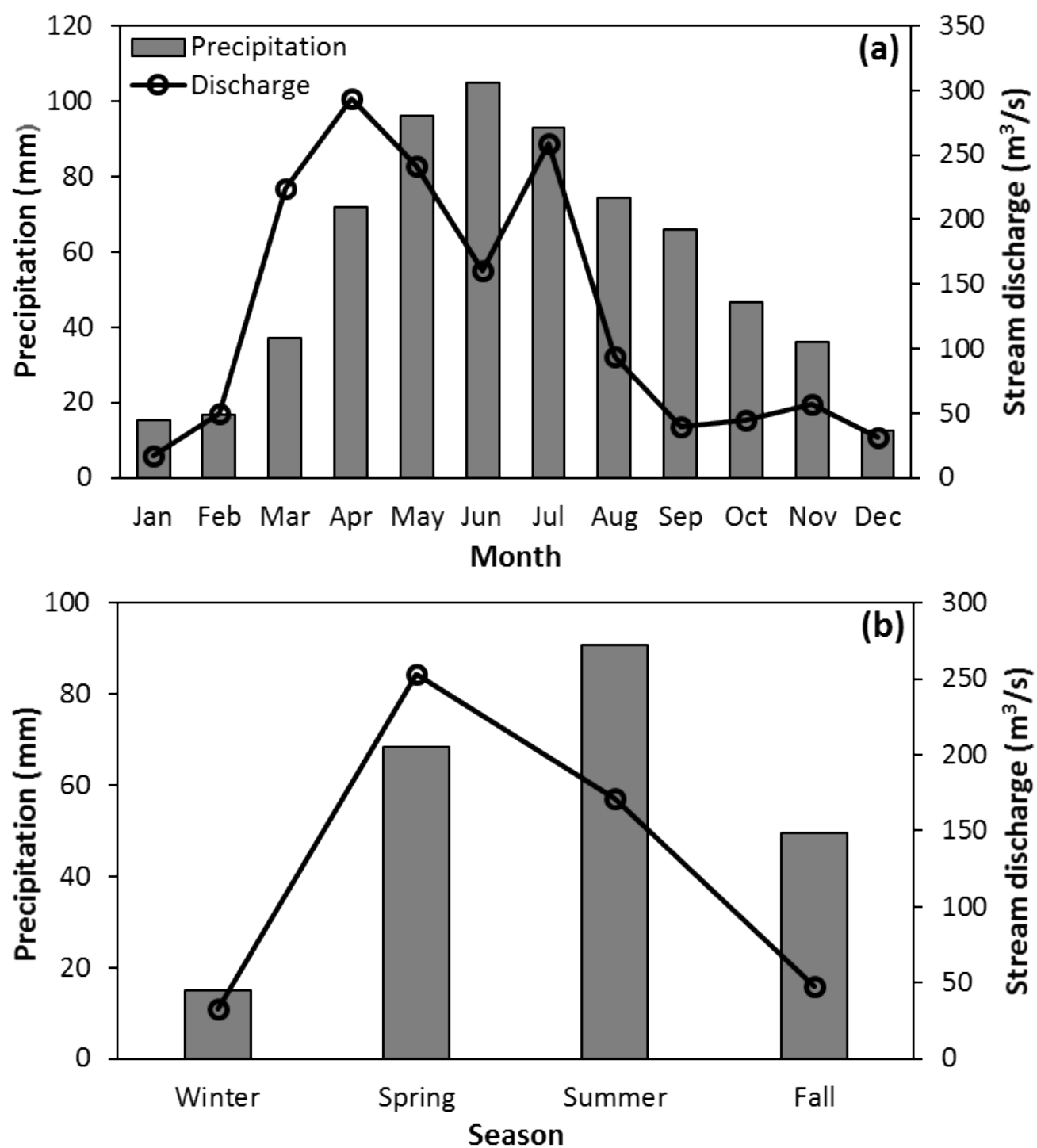

Figure 4: Hydrographs to show the average precipitation and stream discharge in the Skunk Creek basin for monthly (a) and seasonal (b) time periods.

Similar to these findings, Kannan et al. [67] also suggested that the soil water capacity correlated with various water balance components. In addition, SOL_AWC is considered to be directly proportional to the ability of soil to hold water affecting the stream flow. Similarly, the higher sensitivity of the $\mathrm{CN} 2$ is attributed to the higher influence of runoff generation in the basin [68]. However, the SMFMN which was moderately sensitive for 500 simulations was observed the least sensitive parameter for 2000 simulations. The ranking of most sensitive parameters observed in this study was also supported by the findings of Faramarzi et al. $[62,67]$.

It was found that the parameter rankings impact the value of objective function when we altered the number of model simulations; though the change was small. However, we found larger changes when the simulation change was accompanied with the increasing iterations. In the latter case, we obtained the narrower parameter range with the maximum objective function values. The new fitted values were also observed beyond the limit of meaningful physical range of SWAT parameters. Therefore, these assessments demonstrated that awareness about meaningful physical range of hydrologic parameters is crucial while working with semi-automated stochastic calibration tool to monitor water balance components of a watershed system.

\section{Dotty plots}

The dotty plots mapped the model parameter and objective function values to help in identifying the relative sensitivity associated with each parameter influencing the objective function [69]. The plots obtained for 500 and 2000 simulations showed that there was trend followed by the points (corresponding to every simulation in an iteration) in case of SOL_AWC and CN2 that was influencing the objective function unlike with other parameters (Figures 6 and 7). Therefore, the SOL_AWC and $\mathrm{CN} 2$ were observed to be the most sensitive parameter in both the cases. This process also helped to define the new range of values for the parameters that further decided the best fitted values to work for next iteration level. With change in number of simulations and iterations, the range and best fitted values of the parameters were also changed 
Citation: Mehan S, Neupane RP, Kumar S (2017) Coupling of SUFI 2 and SWAT for Improving the Simulation of Streamflow in an Agricultural Watershed of South Dakota. Hydrol Current Res 8: 280. doi: 10.4172/2157-7587.1000280
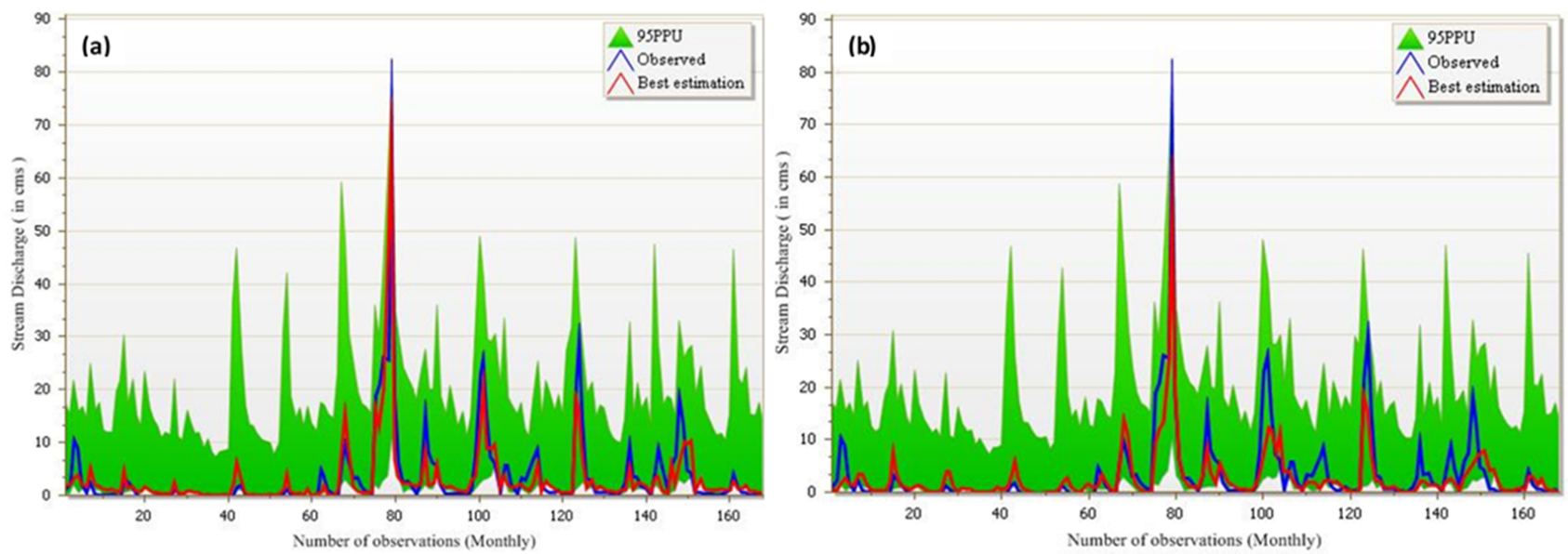

Figure 5: 95 PPU plots derived from running SUFI-2 within the SWAT-CUP for different number of simulations: (a) for 500 and (b) for 2000 simulations.

(a) R_SOL_AWC(..)sol

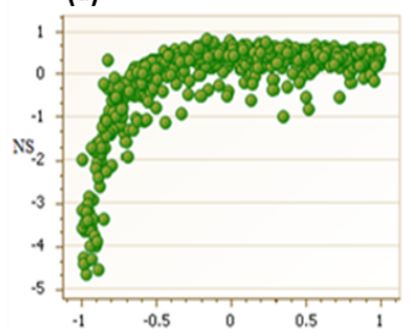

(e) R_SLSUBBSNhu

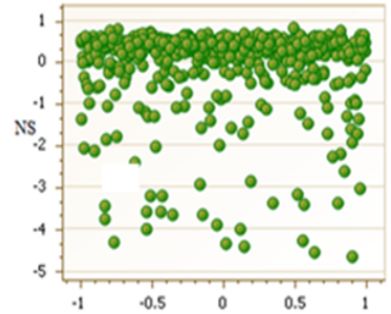

(b) R_CN2m

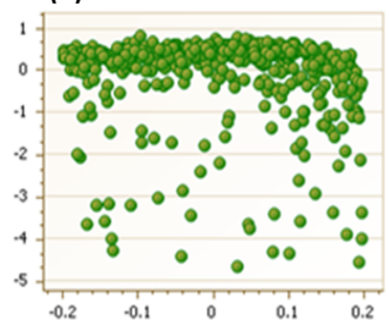

(f) V_ALPHA_BF.gw

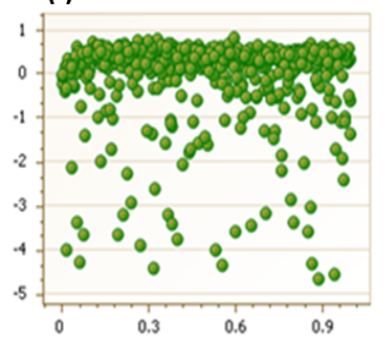

(c) V_SMPXbs

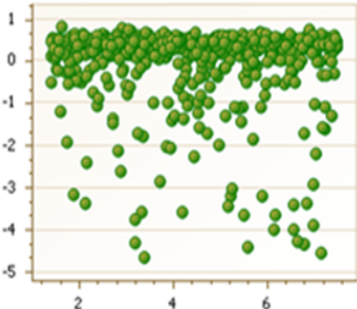

(g) V_FFCB.bo

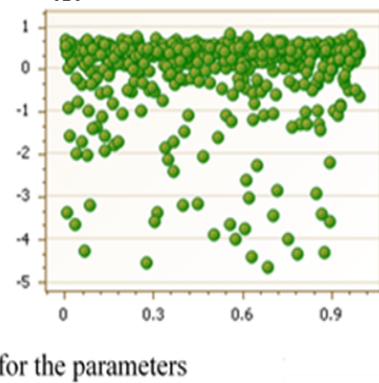

(d) R_HEAT_UNITS\{-.\}m

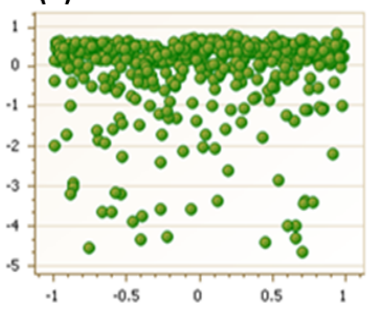

Figure 6: The dotty plots derived from SUFI-2 for 500 simulations are shown for the most and least sensitive parameters used in this study (Note: the above plots (a to d) are for the most sensitive and the below plots (e to $h$ ) are for the least sensitive parameters).

\begin{tabular}{|c|c|c|c|c|c|}
\hline \multirow{2}{*}{ Statistics } & \multicolumn{2}{|c|}{ Pre-calibration } & \multicolumn{2}{|c|}{ Calibration (1987-1994) } & Malidation (1995-2000) \\
\hline & Daily & Monthly & Daily & Monthly & 0.84 \\
\hline NSE $^{\dagger}$ & -1.4 & 0.59 & 0.56 & -9.53 & -16.3 \\
\hline PBIAS & -4.22 & -4.64 & -9.7 & 38.67 & -5.18 \\
\hline RMSE & 1178.38 & 71.44 & 411.39 & 0.76 & 292.75 \\
\hline$R^{2}$ & 0.18 & 0.59 & 0.7 & 0.44 \\
\hline
\end{tabular}

†NSE=Nash-Sutcliffe Efficiency, PBIAS=Percent bias

Table 2: Calibration and validation of stream flow simulated using Soil and Water Assessment Tool coupled with semi-automated SWAT-CUP. 
Citation: Mehan S, Neupane RP, Kumar S (2017) Coupling of SUFI 2 and SWAT for Improving the Simulation of Streamflow in an Agricultural Watershed of South Dakota. Hydrol Current Res 8: 280. doi: 10.4172/2157-7587.1000280

(a) R_SOL_AWC(..).sol

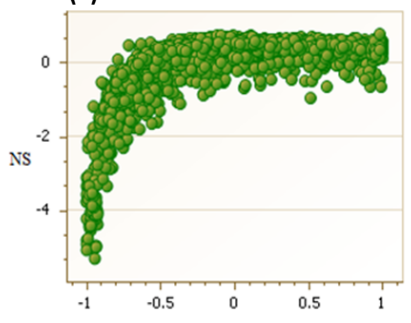

(b) R_CN2mg

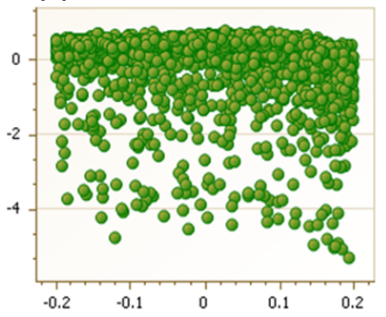

(c) R_SOL_K(..).sol

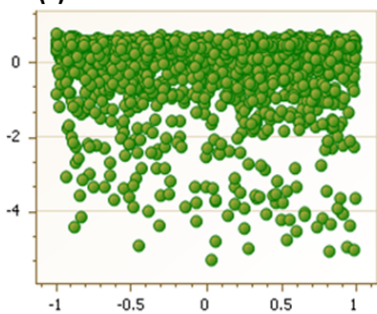

(d) V_SMTMP.bsn

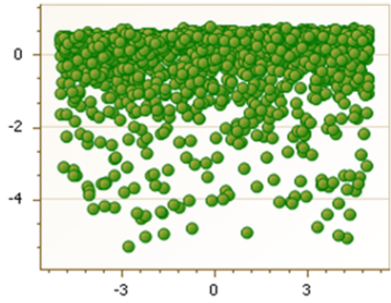

(e) V_SURLAG.bm

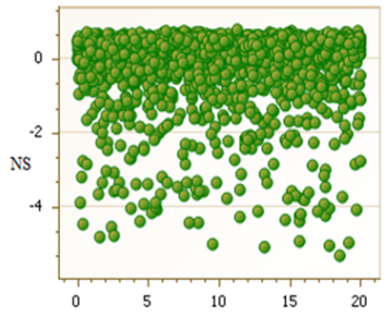

(f) V_GW_DELAY.gw

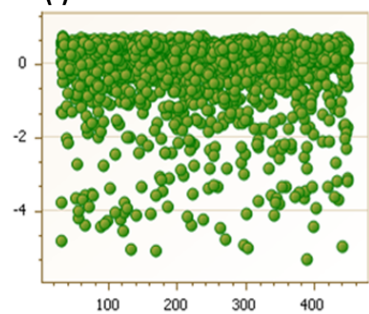

(g) R_sOL_BD(..).50l

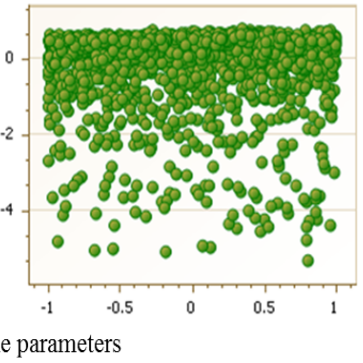

(h) V_SMFMN.bon

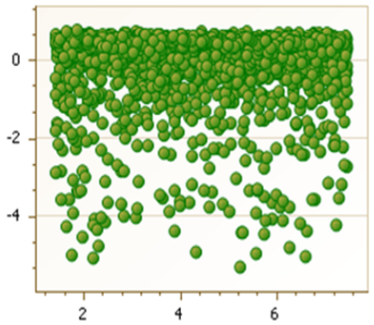

Figure 7: The dotty plots derived from SUFI-2 for 2000 simulations are shown for the most and least sensitive parameters used in this study (Note: the above plots (a to d) are for the most sensitive and the below plots (e to $h$ ) are for the least sensitive parameters).

\begin{tabular}{|c|c|c|c|c|c|c|c|}
\hline \multirow{2}{*}{ S. No. } & \multirow{2}{*}{ Name of the Parameter } & \multicolumn{3}{|c|}{500 Simulations } & \multicolumn{3}{|c|}{2000 Simulations } \\
\hline & & t-stat & $p$-value & Rank & t-stat & $p$-value & Rank \\
\hline 1 & R_SOL_AWC.sol & 17.5021 & 0 & 1 & 35.1897 & 0 & 1 \\
\hline 2 & R_CN2.mgt & 5.3899 & 0 & 2 & 9.9696 & 0 & 2 \\
\hline 3 & V_SMFMX.bsn & 2.8783 & 0.0042 & 3 & 1.4666 & 0.1426 & 6 \\
\hline 4 & R_HEAT_UNITS.mgt & 2.6382 & 0.0086 & 4 & 1.7713 & 0.0767 & 5 \\
\hline 5 & V_ESCO.bsn & 1.7789 & 0.0759 & 5 & 0.468 & 0.6398 & 19 \\
\hline 6 & V_SMTMP.bsn & 1.7157 & 0.0869 & 6 & 2.0229 & 0.0432 & 4 \\
\hline 7 & V_SURLAG.bsn & 1.5762 & 0.1156 & 7 & 0.3649 & 0.7152 & 21 \\
\hline 8 & V_GWQMN.gw & 1.2763 & 0.2025 & 8 & 1.1644 & 0.2444 & 9 \\
\hline 9 & V_GW_DELAY.gW & 1.2154 & 0.2248 & 9 & 0.2886 & 0.7729 & 22 \\
\hline 10 & V_CH_N2.rte & 1.1364 & 0.2563 & 10 & 1.2014 & 0.2297 & 8 \\
\hline 11 & V_SMFMN.bsn & 0.9263 & 0.3548 & 11 & 0.0259 & 0.9793 & 24 \\
\hline 12 & V_RCHRG_DP.gw & 0.901 & 0.368 & 12 & 0.7988 & 0.4245 & 14 \\
\hline 13 & R_OV_N.hru & 0.8255 & 0.4095 & 13 & 1.1465 & 0.2517 & 10 \\
\hline 14 & V_GW_REVAP.gw & 0.7058 & 0.4807 & 14 & 0.64 & 0.5222 & 16 \\
\hline 15 & R_SOL_K.sol & 0.5995 & 0.5491 & 15 & 2.3892 & 0.017 & 3 \\
\hline 16 & V_SHALLST.gw & 0.5914 & 0.5545 & 16 & 0.7089 & 0.4784 & 15 \\
\hline 17 & V_REVAPMN.gw & 0.5027 & 0.6154 & 17 & 0.8951 & 0.3708 & 13 \\
\hline 18 & V_SFTMP.bsn & 0.4974 & 0.6191 & 18 & 0.4151 & 0.6781 & 20 \\
\hline 19 & V_EPCO.bsn & 0.3868 & 0.6991 & 19 & 0.5926 & 0.5535 & 18 \\
\hline 20 & R_SOL_BD.sol & 0.2467 & 0.8053 & 20 & 0.0839 & 0.9331 & 23 \\
\hline 21 & R_SLSUBBSN.hru & 0.1353 & 0.8924 & 21 & 1.1177 & 0.2639 & 12 \\
\hline 22 & V_ALPHA_BF.gw & 0.1036 & 0.9175 & 22 & 1.4637 & 0.1435 & 7 \\
\hline 23 & V_FFCB.bsn & 0.0469 & 0.9626 & 23 & 1.1402 & 0.2543 & 11 \\
\hline 24 & V_CH_K2.rte & 0.0282 & 0.9775 & 24 & 0.5969 & 0.5506 & 17 \\
\hline
\end{tabular}

Table 3: Impact of number of simulations on sensitivity analysis of parameters chosen to calibrate the SWAT model using SUFI-2. 
(Table 4). For 500 simulations, the best fitted value for CN2 (where maximum NS approximately approached to 1) was observed to be approximately -0.1 . However, as the simulations increased to higher number (2000 in our case), the value shifted to around 0.02 . The relative sensitivity of each parameter was estimated by observing the impact on an objective function using the dotty plots. It was concluded that if the points on dotty plots are scattered or haphazard; the sensitivity is low for the parameter and if the points do follow a trend, the sensitivity is higher.

\section{Superiority in using SUFI-2 over other algorithms}

The SUFI-2 tool involves stochastic calibration, where the errors and uncertainties in model are recognized and expressed as ranges accounting for all driving variables, conceptual model, parameters and measured data [60]. The provision of inclusion of large number of parameters representing different processes in the objective function, in SUFI-2, helps to make the model result enveloping most of the observations well [70]. While simulating runoff and sediment modeling using SWAT in Gumera catchment in Ethiopia, used two approaches for calibration. They were fully automated Parameter Solution (ParaSol) and semi-automated Sequential Uncertainty Fitting 2 (SUFI-2) for the period from 2003 to 2006 . They carried out calibration using 13 runoff producing parameters and concluded that SUFI- 2 was more flexible to work with than Parasol and yielded higher values for coefficient of determination and NSE coefficient. Luo et al. [71] in their research on carrying calibration and uncertainty analysis of Japanese river
Catchment using SWAT model using GLUE and SUFI-2 algorithm concluded that though the calibration results improved using GLUE approach but the processing time of GLUE approach is longer than SUFI2. In contrast to this, research carried by Singh et al. [54] showed that coefficient of determination and NSE was found to get reduced while using GLUE algorithm on daily time step. Even results inferred from this study also improved using SUFI-2, which can be seen in having more improved values for statistical evaluating parameters in case of calibration when compared with pre-calibration. This was possible because it reduced the uncertainty among the parameters and helped to build a highly reliable model with higher objective function of simulating the stream discharge relative close to observed values. This makes SUFI-2 to stand out from most of algorithms used for carrying calibration and uncertainty analysis of a hydrologic model because, in SUFI-2, uncertainty among the parameters accounts for various sources like uncertainties in input data, conceptual model, and among parameters itself because desegregation of the error into its source components is complex, especially in cases pertaining to hydrologic modeling where the models are nonlinear and different sources of error may interact to produce measured deviation $[72,73]$.

\section{Summary and Conclusions}

The ArcGIS enabled SWAT (ArcSWAT) model was used to simulate stream flow from the Skunk Creek watershed using 24 different key hydrologic parameters. Parameterization, and uncertainty and sensitivity analyses were carried out using the SUFI-2 approach within

\begin{tabular}{|c|c|c|c|c|c|c|c|c|}
\hline \multirow{2}{*}{ Name of the Parameter } & \multicolumn{2}{|c|}{ Original Range } & \multicolumn{3}{|c|}{500 Simulations } & \multicolumn{3}{|c|}{2000 Simulations } \\
\hline & Min & $\operatorname{Max}$ & Fitted Value & New Min & New Max & Fitted Value & New Min & New Max \\
\hline R_CN2.mgt & -0.2 & 0.2 & -0.097 & -0.245 & 0.051 & 0.026 & -0.086 & 0.14 \\
\hline V_ALPHA_BF.gw & 0 & 1 & 0.595 & 0.297 & 0.892 & 0.104 & -0.342 & 0.552 \\
\hline V_GW_Delay.gw & 30 & 450 & 354.66 & 192.288 & 517.031 & 367.785 & 198.887 & 536.682 \\
\hline V_GWQMN.gw & 0 & 2 & 1.11 & 0.554 & 1.665 & 1.507 & 0.753 & 2.261 \\
\hline V_SFTMP.bsn & -5 & 5 & 3.29 & -0.856 & 7.436 & 1.382 & -1.808 & 4.573 \\
\hline V_SMFMX.bsn & 1.4 & 7.5 & 1.637 & -1.293 & 4.569 & 6.129 & 3.764 & 8.493 \\
\hline V_SMFMN.bsn & 1.4 & 7.5 & 5.419 & 3.409 & 7.43 & 1.855 & -0.966 & 4.678 \\
\hline V_SMTMP.bsn & -5 & 5 & 2.51 & -1.246 & 6.266 & -0.152 & -2.728 & 2.423 \\
\hline V_SHALLST.gw & 0 & 5 & 0.145 & -2.283 & 2.573 & 2.758 & 1.379 & 4.138 \\
\hline V_GW_REVAP.gW & 0.02 & 0.2 & 0.08 & 0.021 & 0.14 & 0.125 & 0.072 & 0.178 \\
\hline V_REVAPMN.gw & 0 & 100 & 59.1 & 29.54 & 88.659 & 87.875 & 43.936 & 131.813 \\
\hline V_RCHRG_DP.gw & 0 & 1 & 0.025 & -0.462 & 0.512 & 0.239 & -0.141 & 0.619 \\
\hline V_ESCO.bsn & 0.01 & 1 & 0.943 & 0.476 & 1.41 & 0.405 & 0.107 & 0.702 \\
\hline V_EPCO.bsn & 0.01 & 1 & 0.923 & 0.466 & 1.38 & 0.592 & 0.301 & 0.884 \\
\hline V_FFCB.bsn & 0 & 1 & 0.559 & 0.279 & 0.838 & 0.16 & -0.259 & 0.58 \\
\hline R_SLSUBBSN.hru & -1 & 1 & 0.49 & -0.255 & 1.235 & 0.789 & -0.105 & 1.684 \\
\hline R_HEAT_UNITS.mgt & -1 & 1 & 0.95 & -0.025 & 1.925 & 0.61 & -0.194 & 1.415 \\
\hline R_OV_N.hru & -1 & 1 & -0.394 & -1.091 & 0.303 & -0.763 & -1.645 & 0.118 \\
\hline R_SOL_K.sol & -1 & 1 & -0.998 & -1.997 & 0.001 & -0.997 & -1.996 & 0.001 \\
\hline R_SOL_AWC.sol & -1 & 1 & -0.162 & -0.743 & 0.419 & 0.973 & -0.013 & 1.96 \\
\hline R_SOL_BD.sol & -1 & 1 & 0.638 & -0.181 & 1.457 & 0.348 & -0.325 & 1.022 \\
\hline V_SURLAG.bsn & 0.001 & 20 & 5.86 & -1.211 & 12.932 & 11.295 & 5.647 & 16.942 \\
\hline V_CH_K2.rte & 0 & 150 & 106.05 & 53.01 & 159.089 & 19.387 & -45.92 & 84.695 \\
\hline V_CH_N2.rte & 0.01 & 0.15 & 0.053 & 0.004 & 0.1015 & 0.094 & 0.052 & 0.136 \\
\hline
\end{tabular}

Table 4: Range of initial values selected for the calibration of SWAT model using SUFI-2, and impact of number of simulations on fitted values and new range of parameters for the subsequent iterations. 
Citation: Mehan S, Neupane RP, Kumar S (2017) Coupling of SUFI 2 and SWAT for Improving the Simulation of Streamflow in an Agricultural Watershed of South Dakota. Hydrol Current Res 8: 280. doi: 10.4172/2157-7587.1000280

the SWAT-CUP. Our simulation results showed a reasonable accuracy between measured and model simulated stream flow values. The SWATCUP improved the stream flow simulations, and reducing uncertainty among the parameters. It was observed that due to the inclusion of larger confidential interval in less sensitive parameters, the uncertainty reduction among these parameters took more time than more sensitive parameters. Moreover, during parameterization process, awareness of physical meaningful range of parameters chosen for calibration led to better simulation results. It was also observed that in order to maximize the objective function, optimum number of iterations and simulations should be performed, else the best fitted value for the parameters may go beyond acceptable range. Finally, semi-automated stochastic model, the SWAT-CUP improved the SWAT simulations of stream flow with the meaningful physical acceptable range of the key hydrologic parameters and higher statistical evaluating parameters depicting more reliability of simulated results.

\section{Acknowledgements}

This study was a part of the project supported by the United States Department of Agriculture-NIFA (Award No. 2014-51130-22593) entitled "Integrated plan for drought preparedness and mitigation, and water conservation at watershed scale".

\section{References}

1. Abbaspour KC, Yang J, Maximov I, Siber R, Bogner K, et al. (2007) Modelling hydrology and water quality in the pre-alpine/alpine Thur watershed using SWAT. Journal of hydrology 333: 413-430.

2. Fekete BM, Vörösmarty CJ (2007) The current status of global river discharge monitoring and potential new technologies complementing traditional discharge measurements. Predictions in Ungauged Basins: PUB kick-off (Proceedings of the PUB kick-off meeting held in Brasilia IAHS Publication 309.

3. Johanson RC, Imhoff JC, Kittle JL, Donigian AS (1984) Hydrological simulation program-FORTRAN (HSPF): user's manual for release 8.0: NTIS.

4. Abbott M, Bathurst J, Cunge J, O'connell P, Rasmussen J (1986) An introduction to the European Hydrological System-Systeme Hydrologique Europeen "SHE", 2: Structure of a physically-based, distributed modelling system. Journal of hydrology $87:$ 61-77.

5. Refsgaard J, Storm B (1995) Mike she. Chapter 23 in computer models of watershed hydrology, 809-846. VP Singh ed. Water Resources Pub, Highlands Ranch, CO.

6. Bathurst J, Wicks J, O'Connell P, Singh V (1995) The SHE/SHESED basin scale water flow and sediment transport modelling system. Computer models of watershed hydrology: 563-594

7. Arnold JG, Allen PM, Bernhardt G (1993) A comprehensive surfacegroundwater flow model. Journal of hydrology 142: 47-69.

8. Ambroise B, Beven K, Freer J (1996) Toward a generalization of the TOPMODEL concepts: Topographic indices of hydrological similarity. Water Resources Research 32: 2135-2145.

9. Ambroise B, Freer J, Beven K (1996) Application of a generalized TOPMODEL to the small Ringelbach catchment, Vosges, France. Water Resources Research 32: 2147-2159.

10. Braunschweig F, Leitao P, Fernandes L, Pina P, Neves R (2004) The object-oriented design of the integrated water modelling system MOHID. Developments in Water Science 55: 1079-1090.

11. Epelde A, Cerro I, Sánchez-Pérez J, Sauvage S, Srinivasan R, et al. (2015) Application of the SWAT model to assess the impact of changes in agricultural management practices on water quality. Hydrological Sciences Journal (aheadof-print): $1-19$

12. Bracmort K, Arabi M, Frankenberger J, Engel B, Arnold J (2006) Modeling longterm water quality impact of structural BMPs. Transactions of the ASAE 49: 367-374

13. Neupane RP, Kumar S (2015) Estimating the effects of potential climate and land use changes on hydrologic processes of a large agriculture dominated watershed. Journal of Hydrology 529: 418-429.

14. Santhi C, Arnold JG, Williams JR, Dugas WA, Srinivasan R, et al. (2001)
Validation of the swat model on a large rwer basin with point and nonpoint sources. JAWRA: Journal of the American Water Resources Association 37 1169-88.

15. Schuol J, Abbaspour KC, Yang H, Srinivasan R, Zehnder AJ (2008) Modeling blue and green water availability in Africa. Water Resources Research 44: W07406.

16. Uniyal B, Jha MK, Verma AK (2015) Assessing Climate Change Impact on Water Balance Components of a River Basin Using SWAT Model. Water Resour Manage 29: 4767-4785.

17. Gassman PW, Reyes MR, Green CH, Arnold JG (2007) The soil and water assessment tool: historical development, applications, and future research directions. Transactions of the ASABE 50: 1211-1250.

18. Williams J, Arnold J, Kiniry J, Gassman P, Green C (2008) History of mode development at Temple, Texas. Hydrological sciences journal 53: 948-960.

19. Singh VP, Woolhiser DA (2002) Mathematical modeling of watershed hydrology. Journal of hydrologic engineering 7: 270-292.

20. Xuan Y, Cluckie I, Wang Y (2009) Uncertainty analysis of hydrological ensemble forecasts in a distributed model utilising short-range rainfall prediction Hydrology and Earth System Sciences 13: 293-303.

21. Van Griensven A, Meixner T, Grunwald S, Bishop T, Diluzio M, et al. (2006) A global sensitivity analysis tool for the parameters of multi-variable catchment models. Journal of hydrology 324: 10-23.

22. Beven K, Binley A (1992) The Future of Distributed Models: Model Calibration and Uncertainty Prediction. Hydrological processes 6: 279-298.

23. Vrugt JA, Gupta HV, Bouten W, Sorooshian S (2003) A Shuffled Complex Evolution Metropolis algorithm for optimization and uncertainty assessment of hydrologic model parameters. Water Resources Research 39: 1201.

24. Yang J, Reichert $P$, Abbaspour K, Xia J, Yang H (2008) Comparing uncertainty analysis techniques for a SWAT application to the Chaohe Basin in China Journal of Hydrology 358: 1-23.

25. Abbaspour K, Vejdani M, Haghighat S (2007) SWAT-CUP calibration and uncertainty programs for SWAT. MODSIM 2007 International Congress on Modelling and Simulation, Modelling and Simulation Society of Australia and New Zealand 1596-1602.

26. Sloboda M, Swayne D (2011) Autocalibration of environmental process models using a PAC learning hypothesis. Environmental Software Systems Frameworks of eEnvironment, pp: 528-534.

27. Rosso R (1994) An introduction to spatially distributed modelling of basin response. Advances in Distributed Hydrology 3: 30.

28. Sorooshian S, Gupta V (1995) Model calibration. Computer Models of Watershed Hydrology, pp: 23-68.

29. Saltelli A, Chan K, Marian S (2000) Sensitivity Analysis. John Wiley \& Sons: Chichester.

30. Holvoet K, van Griensven A, Seuntjens P, Vanrolleghem P (2005) Sensitivity analysis for hydrology and pesticide supply towards the river in SWAT. Physics and Chemistry of the Earth, Parts A/B/C 30: 518-526.

31. Spruill C, Workman S, Taraba J (2000) Simulation of daily and monthly stream discharge from small watersheds using the SWAT model. Transactions of the ASAE 43: 1431-1439.

32. Turanyi T, Rabitz H (2000) Local methods. Sensitivity Analysis, pp: 81-99.

33. Helton JC (1993) Uncertainty and sensitivity analysis techniques for use in performance assessment for radioactive waste disposal. Reliability Engineering \& System Safety 42: 327-367.

34. Lilburne L, Gatelli D, Tarantola S (2006) Sensitivity analysis on spatial models: new approach. Proceedings of the 7 th international symposium on spatial accuracy assessment in natural resources and environmental sciences: Citeseer.

35. Arnold J, Moriasi D, Gassman P, Abbaspour K, White M, et al. (2012) SWAT: Model use, calibration, and validation. Transactions of the ASABE 55: 1491 1508.

36. Cibin R, Sudheer K, Chaubey I (2010) Sensitivity and identifiability of stream flow generation parameters of the SWAT model. Hydrological Processes 24 1133-1148. 
Citation: Mehan S, Neupane RP, Kumar S (2017) Coupling of SUFI 2 and SWAT for Improving the Simulation of Streamflow in an Agricultural Watershed of South Dakota. Hydrol Current Res 8: 280. doi: 10.4172/2157-7587.1000280

37. Strom R, Gilbertson J (2010) Appendices for the Central Big Sioux River Watershed Project-Segment 1 Final Report.

38. Kaur R, Singh O, Srinivasan R, Das S, Mishra K (2004) Comparison of a subjective and a physical approach for identification of priority areas for soil and water management in a watershed-a case study of Nagwan watershed in Hazaribagh District of Jharkhand, India. Environmental Modeling \& Assessment 9: 115-127.

39. Neupane RP, White JD, Alexander SE (2015) Projected hydrologic changes in monsoon-dominated Himalaya Mountain basins with changing climate and deforestation. Journal of Hydrology 525: 216-230.

40. Fontaine T, Klassen J, Cruickshank T, Hotchkiss R (2001) Hydrological response to climate change in the Black Hills of South Dakota, USA Hydrological Sciences Journal 46: 27-40.

41. Jha M, Arnold JG, Gassman PW, Giorgi F, Gu RR (2006) Climate change sensitivity assessment on upper mississippi river basin streamflows using SWAT. JAWRA Journal of the American Water Resources Association 42: 997-1015.

42. Neitsch SL, Arnold JG, Kiniry JR, Williams JR (2011) Soil and water assessment tool theoretical documentation version 2009. Texas Water Resources Institute.

43. Hargreaves GL, Hargreaves GH, Riley JP (1985) Agricultural benefits for Senegal River basin. Journal of irrigation and Drainage Engineering 111: 113124

44. Priestley C, Taylor R (1972) On the assessment of surface heat flux and evaporation using large-scale parameters. Monthly Weather Review 100: 8192.

45. Monteith J (1965) Evaporation and environment. Symp Soc Exp Biol, p: 4.

46. Allen RG (1986) A Penman for all seasons. Journal of Irrigation and Drainage Engineering 112: 348-368.

47. USDA (1972) National Engineering Handbook, Section 4: Hydrology. Washington, DC.

48. Staff UN (2011) Web soil survey. Natural Resources Conservation Service, United States Department of Agriculture.

49. Thornton PE, Running SW, White MA (1997) Generating surfaces of daily meteorological variables over large regions of complex terrain. Journal of Hydrology 190: 214-251.

50. Thornton PE, Thornton MM, Mayer BW, Wilhelmi N, Wei Y, et al. (2012) Daymet: Daily surface weather on a $1 \mathrm{~km}$ grid for North America, 1980-2008. Oak Ridge National Laboratory (ORNL) Distributed Active Archive Center for Biogeochemical Dynamics (DAAC)

51. Keane RE, Holsinger LM, Parsons RA, Gray K (2008) Climate change effects on historical range and variability of two large landscapes in western Montana, USA. Forest Ecology and Management 254: 375-389.

52. Oubeidillah AA, Kao SC, Ashfaq M, Naz BS, Tootle G (2014) A large-scale, high-resolution hydrological model parameter data set for climate change impact assessment for the conterminous US. Hydrology and Earth System Sciences 18: 67-84.

53. Feyereisen G, Strickland T, Bosch D, Sullivan D (2007) Evaluation of SWAT manual calibration and input parameter sensitivity in the Little River watershed. Trans ASABE 50: 843-855.

54. Singh V, Bankar N, Salunkhe SS, Bera AK, Sharma J (2013) Hydrologica stream flow modelling on Tungabhadra catchment: parameterization and uncertainty analysis using SWAT CUP. Current Science (Bangalore) 104: 1187-1199.

55. Moriasi D, Arnold J, Van Liew M, Bingner R, Harmel R, et al. (2007) Mode evaluation guidelines for systematic quantification of accuracy in watershed simulations. Trans Asabe 50: 885-900.

56. Nash J, Sutcliffe JV (1970) River flow forecasting through conceptual models' part I-A discussion of principles. Journal of hydrology 10: 282-290.
57. Gupta HV, Sorooshian S, Yapo PO (1998) Toward improved calibration of hydrologic models: Multiple and noncommensurable measures of information. Water Resources Research 34: 751-763.

58. McKay MD, Beckman RJ, Conover WJ (1979) Comparison of three methods for selecting values of input variables in the analysis of output from a computer code. Technometrics 21: 239-245.

59. Press WH, Teukolsky SA, Vetterling WT, Flannery BP (1992) Numerical Recipes: The art of scientific computing Cambridge. Cambridge Univ Press.

60. Abbaspouri KC (2015) SWAT-CUP: SWAT Calibration and Uncertainty program- A user manual. EAWAG.

61. Groisman PY, Knight RW, Karl TR (2001) Heavy precipitation and high streamflow in the contiguous United States: Trends in the twentieth century. Bulletin of the American Meteorological Society 82: 219-246.

62. Faramarzi M, Abbaspour KC, Schulin R, Yang H (2009) Modelling blue and green water resources availability in Iran. Hydrological Processes 23: 486-501.

63. Abrishamchi A, Tajrishi M (2005) Interbasin water transfer in Iran. Water conservation, reuse, and recycling: Proceeding of an Iranian American Workshop, pp: 252-271.

64. Abbaspour K (2011) User manual for SWAT-CUP. Eawag: Swiss Fed. Inst of Aquat. Sci and Technol, Duebendorf, Switzerland. SWAT Calibration and Uncertainty Analysis Programs, p: 103.

65. Abbaspour K (2013) SWAT-CUP 2012: SWAT calibration and uncertainty programs - A user manual. Eawag: Dübendorf, Switzerland, p: 103.

66. Burba GG, Verma SB (2005) Seasonal and interannual variability in evapotranspiration of native tallgrass prairie and cultivated wheat ecosystems. Agricultural and Forest Meteorology 135: 190-201.

67. Kannan N, White S, Worrall F, Whelan M (2007) Sensitivity analysis and identification of the best evapotranspiration and runoff options for hydrological modelling in SWAT-2000. Journal of Hydrology 332: 456-466.

68. Opere A, Okello B (2011) Hydrologic analysis for river Nyando using SWAT. Hydrology and Earth System Sciences Discussions 8: 1765-1797.

69. Wagener T, Kollat J (2007) Numerical and visual evaluation of hydrological and environmental models using the Monte Carlo analysis toolbox. Environmental Modelling \& Software 22: 1021-1033.

70. Mamo KHM, Jain MK (2013) Runoff and Sediment Modeling Using SWAT in Gumera Catchment, Ethiopia. Open Journal of Modern Hydrology 3: 196.

71. Luo P, Takara K, He B, Cao W, Yamashiki Y, et al. (2011) Calibration and Uncertainty Analysis of Swat Model in a Japanese River Catchment. Annual Journal of Hydraulic Engineering JSCE 55: 61-66.

72. Gupta HV, Beven KJ, Wagener T (2005) Model calibration and uncertainty estimation. Encyclopedia of Hydrological Sciences.

73. Mehan S, Kanan N, Neupane RP, McDaniel R, Kumar S (2016) Climate change impacts on the hydrological processes of a small agricultural watershed. Climate 4: 56. 